\title{
Removal of Vaporous Naphthalene Using Polyoxyethylenated Nonionic Surfactants
}

\author{
Hsiao-Lin Huang and Whei-May Grace Lee \\ Graduate Institute of Environmental Engineering, National Taiwan University, Taipei, Taiwan
}

\begin{abstract}
Previous research has demonstrated that an anionic surfactant can increase the solubility of the vapor phases of both naphthalene and sulfur dioxide in water. This study examines the feasibility of removing polycyclic aromatic hydrocarbons (PAHs) during gas absorption by adding the polyoxyethylenated nonionic surfactants tetraethylene glycol monodecyl ether $\left(\mathrm{C}_{10} \mathrm{E}_{4}\right)$, octaethylene glycol monodecyl ether $\left(\mathrm{C}_{10} \mathrm{E}_{8}\right)$, and octaethylene glycol monotetradecyl ether $\left(\mathrm{C}_{14} \mathrm{E}_{8}\right)$, to water. The apparent solubility and absorption rates of naphthalene in surfactant solution were slightly higher than in pure water at a concentration lower than the critical micelle concentration (CMC). However, the apparent equilibrium naphthalene solubility increased linearly in proportion to the concentrations of nonionic surfactants because of the solubilization effect of micelles at concentrations above the CMC. The solubilization effect exceeded that of the reduced mass transfer coefficient, increasing the rate of absorption of vaporous naphthalene. For the four surfactants, the capacity to solubilize naphthalene was in the order $\mathrm{C}_{10} \mathrm{E}_{4}>\mathrm{C}_{14} \mathrm{E}_{8}>\mathrm{C}_{10} \mathrm{E}_{8}>$ sodium dodecyl sulfate (SDS) and was related to the hydrophile-lipophile balance values of the surfactants. The enrichment factors, which can express the degree of naphthalene solubility in solution, were 6.09-14.2 at a surfactant concentration of $0.01 \mathrm{M}$ for
\end{abstract}

\begin{abstract}
IMPLICATIONS
A wet scrubber is the conventional method employed to control acid gases. However, it cannot be used to remove vaporous PAHs because of their low water solubility. Surfactants can form micelles to increase the solubility of HOCs and have been widely applied recently to the remediation of contaminated soil or groundwater. This study not only examined the extent of the solubilization of vaporphase naphthalene in polyoxyethylenated nonionic surfactant solutions but also explored the feasibility of the surfactants employed to control air toxins. The experimental results show that adding nonionic surfactants increases the absorption efficiency of PAHs and provides a good reference for engineers to develop a new control technology for hydrophobic toxic air pollutants by spray or packed tower.
\end{abstract}

the three polyoxyethylenated nonionic surfactants. Empirical findings confirm that adding nonionic surfactants increases the absorption efficiency of hydrophobic organic compounds (HOCs) using spray or packed tower.

\section{INTRODUCTION}

In Taiwan, municipal solid waste and hazardous waste are commonly incinerated because of a lack of landfill space. However, the incineration process always generates dangerous air pollutants, such as polycyclic aromatic hydrocarbons (PAHs), dioxins, furans, sulfur oxides $\left(\mathrm{SO}_{\mathrm{x}}\right)$, and hydrogen chloride $(\mathrm{HCl}) .{ }^{1}$ PAHs are hydrophobic organic compounds (HOCs), which are toxic air pollutants and are classified as carcinogenic or mutagenic substances. More than $80 \%$ of the total concentration of PAHs in incineration flue gas are in the gaseous phase. ${ }^{2}$ For the sake of public health, it is very important to remove PAHs. Although a wet scrubber can be used to remove acidic gas from flue gas effectively, it is of no use in removing PAHs because of their low solubility in water. Therefore, absorption from activated carbon is still by far the most frequently employed technology for gaseous-phase PAH control. ${ }^{3-5}$

Surfactant-enhanced remediation of metal- and organic-contaminated soil and groundwater and the recovery of surfactants have been investigated extensively in recent years. ${ }^{6-8}$ Deshpande et al. ${ }^{9}$ evaluated and presented some surfactant-screening guidelines for ex situ soil washing of three contaminated soils that contained PAHs. In addition, Kanga et al. ${ }^{10}$ showed biosurfactants increased the solubility of PAHs in water more than chemically synthesized surfactants. A surfactant is an amphiphilic compound with a hydrophilic head and a hydrophobic tail. When the surfactant concentration exceeds the critical micelle concentration'(CMC), micelles are formed by individual monomers coalescing with the hydrophobic ends, increasing the solubility of HOCs. ${ }^{11}$ Edwards et al. ${ }^{12,13}$ and Liu et al. ${ }^{14}$ found that the solubility of PAHs in soil/water systems was proportional to the extent to which the concentration of anionic or nonionic surfactant exceeds the CMC. Yeom et al. ${ }^{15}$ and Paterson 
et al. ${ }^{16}$ also demonstrated that micelles of anionic and nonionic surfactants enhanced the efficiency of extracting PAHs from coal tar-contaminated soils. Moreover, Guha et al. ${ }^{17}$ observed that fewer hydrophobic PAHs could be dissolved in the interface between the micelle cores and water, underscoring the tendency of surfactant micelles to increase the solubility of hydrophobic PAHs when various $\mathrm{PAH}$ substances dissolved simultaneously.

In research on gas absorption using surfactants, many studies have addressed low molecular weight gas solubilization using various surfactants and have shown that the apparent solubility of gas increases linearly with the extent to which surfactant concentrations exceed the

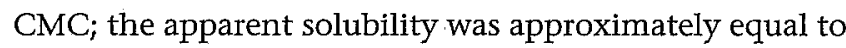
that of pure water at surfactant concentrations below the CMC. ${ }^{18-21}$ For HOCs, Lo and Lee22 stated that the anionic sodium dodecyl sulfate (SDS) surfactant film and mono- mers of surfactant in fog increase $n$-octane solubility at surfactant concentrations below the CMC. Hai et al. ${ }^{23}$ observed that SDS micelles increased methane solubility. Moreover, Steinberg et al. ${ }^{24}$ showed that adding cationic surfactants to soil decreased the absorption of gaseous benzene at a concentration of less than $0.5 \%$ in water but absorption increased at above $1 \%$.

Our previous research demonstrated that the anionic surfactant SDS increases the solubility of vapor-phase PAHs in water. ${ }^{25-27}$ The objectives of this study were to determine whether adding a series of polyoxyethylenated nonionic surfactants to water during the absorption of naphthalene enhanced the solubility of naphthalene and also to compare the feasibility of removing naphthalene with the results of our previous studies. Results of this study can help researchers and industry in selecting the optimal surfactant for removing vapor-phase HOCs.

\section{MODELING}

The mathematical formulation of the absorption model used herein was described in detail in an earlier publication. ${ }^{26}$ The change rate of apparent solubility $C_{\mathrm{T}}$ can be expressed as the following equation:

$$
\frac{d C_{\mathrm{T}}}{d t}=k_{\mathrm{L}}^{\prime}\left(\frac{A}{V_{\mathrm{T}}}\right)\left(C_{\mathrm{T}}^{\mathrm{i}}-C_{\mathrm{T}}\right)
$$

where $C_{\mathrm{T}}$ denotes the solubility of naphthalene within the bulk liquid phase (M); $A$ is the interfacial area of gas/liquid $\left(\mathrm{m}^{2}\right)$; $t$ represents absorption time $(\mathrm{sec})$ and $V_{\mathrm{T}}$ denotes the total volume of absorption liquid $\left(\mathrm{m}^{3}\right) ; k_{\mathrm{L}}{ }^{\prime}$ is defined as the lumped mass transfer coefficient $(\mathrm{m} / \mathrm{sec})$ and $C_{T}^{i}$ denotes the equilibrium naphthalene apparent solubility $(\mathrm{M})$. Given that the initial condition $C_{\mathrm{T}}=0$ at $t=0$, integration of eq 1 produces the following equation:

$$
\begin{aligned}
C_{\mathrm{T}} & =C_{\mathrm{T}}^{\mathrm{i}}\left\{1-\exp \left[\dot{-} k_{\mathrm{L}}^{\prime}\left(\frac{A}{V_{\mathrm{T}}}\right) t\right]\right\} \\
& =C_{\mathrm{T}}^{\mathrm{1}}\left[1-\exp \left(-k_{\mathrm{L}}^{\prime} a^{\prime}\right) t\right]
\end{aligned}
$$

where $a^{\prime}$ is the interfacial area per unit volume of liquid $\left(\mathrm{m}^{2} / \mathrm{m}^{3}\right)$. From eq $2, C_{\mathrm{T}}^{\mathrm{i}}$ and $k_{\mathrm{L}}{ }^{\prime} a^{\prime}$ can be obtained by employing nonlinear regression (Software: Sigma Plot 5.0) of $C_{\mathrm{T}}$ versus $t$.

To represent the dimensionless gas partition ratio between the liquid and gas phase, the apparent Henry's constant, $H^{\prime}$, is defined in eq 3 .

$$
H^{\prime}=\frac{C_{\mathrm{T}^{\mathrm{i}}}^{\mathrm{i}}}{C_{\mathrm{g}}}
$$

where $C_{\mathrm{g}}$ is the naphthalene concentration $(\mathrm{M})$ of the gas phase.

The extent of micellar solubilization of naphthalene can be quantified by the molar solubilization ratio (MSR) and micellar/water partition coefficient $\left(K_{\mathrm{m}}\right)$, defined as follows: ${ }^{13,21}$

$$
M S R=\frac{C_{\mathrm{T}}-C_{\mathrm{T}}^{\mathrm{cmc}}}{C_{\mathrm{mc}}-C M C}
$$

where $C_{\mathrm{mc}}$ denotes the surfactant concentration $(\mathrm{M})$ and $\mathrm{C}_{\mathrm{T}}{ }^{\mathrm{cmc}}$ is the apparent solubility of naphthalene at CMC $(\mathrm{M}) . K_{\mathrm{m}}$ can be expressed as $^{28}$

$$
K_{\mathrm{m}}=\frac{X_{\mathrm{m}}}{X_{\mathrm{w}}}
$$

where $X_{\mathrm{m}}$ is the more fraction of naphthalene in the micellar phase and $X_{\mathrm{w}}$ represents the more fraction 'of naphthalene in the aqueous phase. $X_{\mathrm{m}}$ can be expressed in terms of MSR as

$$
X_{\mathrm{m}}=\frac{M S R}{1+M S R}
$$

The more fraction of naphthalene in the aqueous phase, $X_{\mathrm{w}}$ is approximated for dilute solution by

$$
X_{\mathrm{w}}=C_{\mathrm{T}}^{\mathrm{cmc}} V_{\mathrm{w}},
$$

where $V_{\mathrm{w}}$ is the molar volume of water $(0.01803 \mathrm{~L} / \mathrm{mol}$ at $50^{\circ} \mathrm{C}$ ). Then eq 5 becomes

$$
K_{\mathrm{m}}=\frac{55.46 M S R}{C_{\mathrm{T}}^{\mathrm{cmc}}(1+M S R)}
$$


The hydrophile-lipophile balance (HLB) of polyoxyethylenated nonionic surfactants is calculated using the following equation: ${ }^{11}$

$$
H L B=\frac{M_{\mathrm{H}}}{M_{\mathrm{H}}+M_{\mathrm{L}}} \times 20
$$

where $M_{\mathrm{H}}$ is the molecular weight of a hydrophilic group of nonionic surfactant and $M_{\mathrm{L}}$ represents the molecular weight of a lipophilic group of the nonionic surfactant.

\section{EXPERIMENTAL METHODS}

Polyoxyethylenated nonionic surfactants tetraethylene glycol monodecyl ether $\left(\mathrm{C}_{10} \mathrm{E}_{4}, 99 \%\right)$, octaethylene glycol monodecyl ether $\left(\mathrm{C}_{10} \mathrm{E}_{8}, 99 \%\right)$, and octaethylene glycol monotetradecyl ether $\left(C_{14} E_{8}, 99 \%\right)$ were purchased from Nikko Chemical Co. and used without further purification. The physical and chemical properties of naphthalene are like other alternate PAHs, which are nonpolar, semi-volatile HOCs. ${ }^{29}$ Naphthalene is a nontoxic PAH and has higher vapor pressure than other PAHs. Furthermore, naphthalene produces the desired vapor-phase concentration and is easier and less dangerous to apply than any other PAH. Therefore, naphthalene is the PAH surrogate herein. Naphthalene $(>99 \%$, scintillation grade) was purchased from Merck Co. The deionized water employed was manufactured by the Milli-Q reagent water system (Millipore Co., Ltd.). Selected physical and chemical properties of surfactants are presented in Table 1.

Naphthalene was extracted from the surfactant solution with solid-phase microextraction equipment (SPME). ${ }^{30}$ SPME combined the sampling and preconcentration of organic compounds into one procedure, and it desorbs directly into gas chromatograph (GC) after thermal heating. The primary device of SPME was a modified syringe containing a fused silica fiber, which was polydimethylsiloxane-coated with a $7-\mu \mathrm{m}$ film as a stationary phase.

The distribution constant of naphthalene partitioning between liquid and gas phases was different at each surfactant concentration, especially at high surfactant concentrations, so that naphthalene was distributed more in the liquid phase because of micelle formation. It was necessary to increase the extraction temperature and time to get enough naphthalene quantitatively in the vapor phase using SPME to be analyzed by GC. Therefore, a series of extraction experiments were conducted to determine the optimal extraction temperature and time before the actual experiment. The extraction temperature and time are $60^{\circ} \mathrm{C}$ and $40 \mathrm{~min}$. In addition, every standard calibration curve at every surfactant concentration of absorption was created because of the different distribution constant of naphthalene in different surfactant concentration solutions.

A 6-mL sample of surfactant solution was inserted into a $10-\mathrm{mL}$ amber serum vial. The vial was sealed with a Teflon-lined silicone septum and was submerged in a 60 ${ }^{\circ} \mathrm{C}$ controlled-temperature water bath. The SPME fiber penetrated the septum and was exposed to the headspace of the vial. The stir bar then agitated the solution in the vial and began to extract naphthalene. When extraction was finished, naphthalene was quantified through a Hewlett-Packard HP5890 Series II GC, equipped with a photon ionization detector (PID). Naphthalene was separated by a $30 \mathrm{~m} \times 0.53 \mathrm{~mm}$ i.d. SPB-5 fused silica capillary column (Supelco Co.).

To understand the absorption ability of naphthalene, an absorption cell was used to investigate the removal potential of naphthalene by using nonionic surfactants in this study. In fact, the absorption liquid of wet scrubber equipment, such as packed or spray towers, was flowing or rotational. ${ }^{31}$ Therefore, absorption experiments on an agitated solution were performed. For naphthalene absorption, the agitation speed was $600 \mathrm{rpm}$.

Figure 1 illustrates the experimental system. Through a thermostatic water bath, the standard naphthalene diffusion tube and the absorption cell were fixed at a constant temperature of $50.0 \pm 0.1^{\circ} \mathrm{C}$. All absorption experiments were conducted in batch mode. A 50-mL surfactant solution was first added into an absorption glass cell with a $5.04 \mathrm{~cm}$ i.d., $5 \mathrm{~cm}$ in height. The absorption cell was then placed in the thermostatic water bath for 30 min until a

Table 1. Physical and chemical properties of surfactants selected for naphthalene absorption studies.

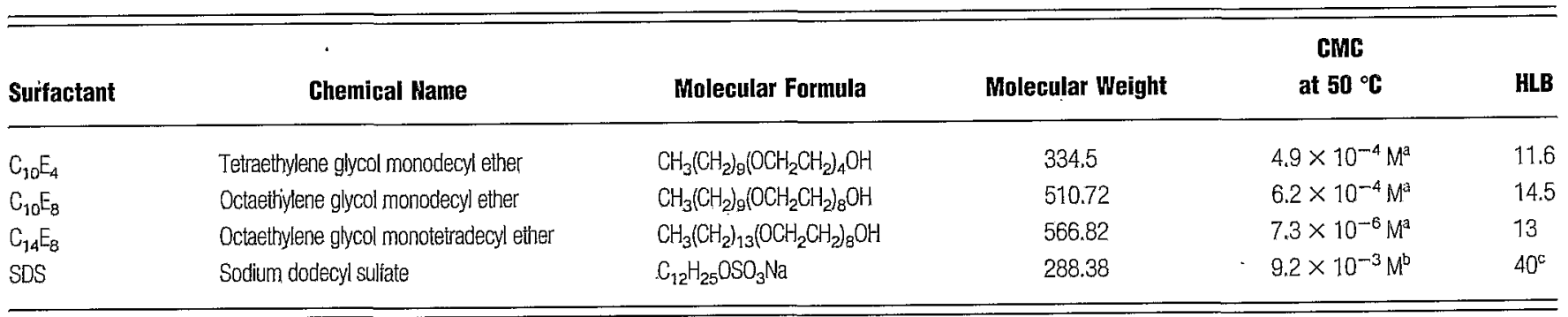

${ }^{\mathrm{a}} \mathrm{CMC}$ data from ref $32 ;{ }^{\mathrm{b}} \mathrm{CMC}$ data from ref $26{ }^{\circ}$ CHLB data from ref 33. 


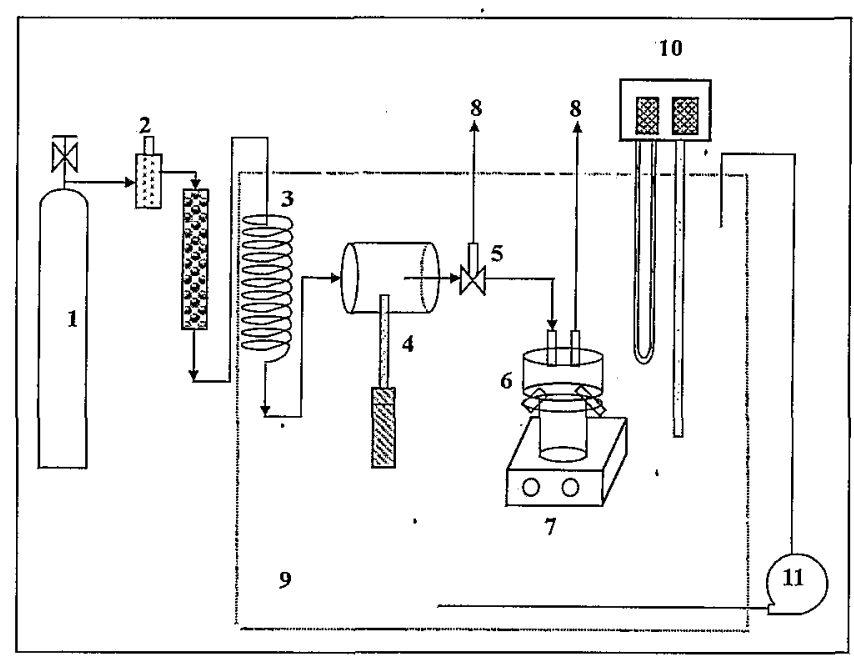

Figure 1. Naphthalene absorption system. $1 . \mathrm{N}_{2}$ cylinder; 2 , electronic mass flow meter: 3 , heat exchanger; 4. naphthalene diffusion íbe; 5 . three-pass valve; 6 . absorption cell; 7 . magnetic stirer; 8 . vent to hood; 9. thermostatic water bath; 10 . themal static controller; 11. pump.

thermal equilibrium between surfactant solution and the bath water was achieved. To generate the required gaseous naphthalene concentration, the vapor naphthalene and nitrogen $\left(\mathrm{N}_{2}\right)$ were mixed. The $\mathrm{N}_{2}$ gas was contained within a cylinder (Chiao-Chung Co., $99.99 \%$ pure) and controlled via an electronic mass flow meter (Sierar Instruments, Inc.). Through a capillary diffusion tube, the naphthalene diffusion tube provided a constant vapor concentration. It is noteworthy that the generated standard naphthalene was $42.8 \mathrm{mg} / \mathrm{m}^{3}$. The experimental surfactant concentrations and the naphthalene absorption time were in the range of $0-0.01 \mathrm{M}$ and $0-300 \mathrm{~min}$, respectively. Subsequently, $6 \mathrm{~mL}$ of the solution was taken from the absorption cell and inserted into a 10-mL vial, and then the experiment was started over again. To determine the naphthalene concentration, each sample was extracted applying SPME equipment and analyzed by GC-PID.

Naphthalene recovery efficiencies were determined by adding known naphthalene concentrations through the same experimental procedure used for the samples. The recovery efficiencies of naphthalene were $~ 96.78$ 103.24\%. Relative standard deviations (RSD) of duplicate analysis of naphthalene were $0.55-4.66 \%$. A blank test for naphthalene was accomplished without adding standard solution before extraction and titration. Analyses of blanks found no significant contamination (under detection limit). The viscosity of surfactant solutions was measured at $50^{\circ} \mathrm{C}$ over a broad range of $0-0.01 \mathrm{M}$ surfactant concentrations both lower and higher than the CMC by viscometer (Brookfield model DV-III with UL spindle, Brookfield Engineering Labs, Inc.).

\section{RESULTS AND DISCUSSION}

Absorption of Naphthalene by Surfactants

Figure 2 presents the naphthalene apparent solubility as a function of time at an agitation speed of $600 \mathrm{rpm}$ for a broad range of $\mathrm{C}_{10} \mathrm{E}_{8}$ nonionic surfactant concentrations lower and higher than the $\mathrm{CMC}$. At surfactant concentrations lower than the $\mathrm{CMC}\left(6.2 \times 10^{-4} . \mathrm{M}\right.$ at $\left.50^{\circ} \mathrm{C}\right), 32$ apparent solubility of naphthalene was similar to that of - pure water and increased only slightly with the surfactant concentration. In this case, the hydrophobicity ability of surfactant monomers enhances naphthalene concentrations. When this occurs between HOCs and nonpolar groups of the diluted surfactant, this is deemed a partition-like interaction. ${ }^{33,34}$ Another cause is that the hydrophobic layer of surfactant monomers, which occurs in the gas/ liquid interface, can adsorb HOCs as well. ${ }^{22}$ However, at surfactant concentrations higher than the CMC, apparent solubility increased dramatically and the absorption rates were significantly greater than those at concentrations lower than the CMC (Figure 3). This is because of the strong inner core force of micelles, which attract naphthalene molecules. It is noteworthy that the absorption mechanism for hydrophobic naphthalene is a solubilization effect of the hydrophobic zone of micelles, which are formed because of an individual surfactant monomer coalesced with the hydrophobic end by van der Waal's force. Similar results were' also shown for the other two nonionic surfactants, $\mathrm{C}_{10} \mathrm{E}_{8}$ and $\mathrm{C}_{14} \mathrm{E}_{8}$, in this study.

\section{Solubilization of Naphthalene by Surfactants}

The equilibrium naphthalene apparent solubility as well as Henry's constants were obtained from eq 2 via a nonlinear regression of $C_{\mathrm{T}}$ versus $t$ as shown in Table 2 . The equilibrium naphthalene apparent solubility or $H^{\prime}$ approximated the apparent solubility or $H^{\prime}$ in pure water when the three polyoxyethylenated nonionic surfactant concentrations were lower than the $\mathrm{CMC}$, and increased

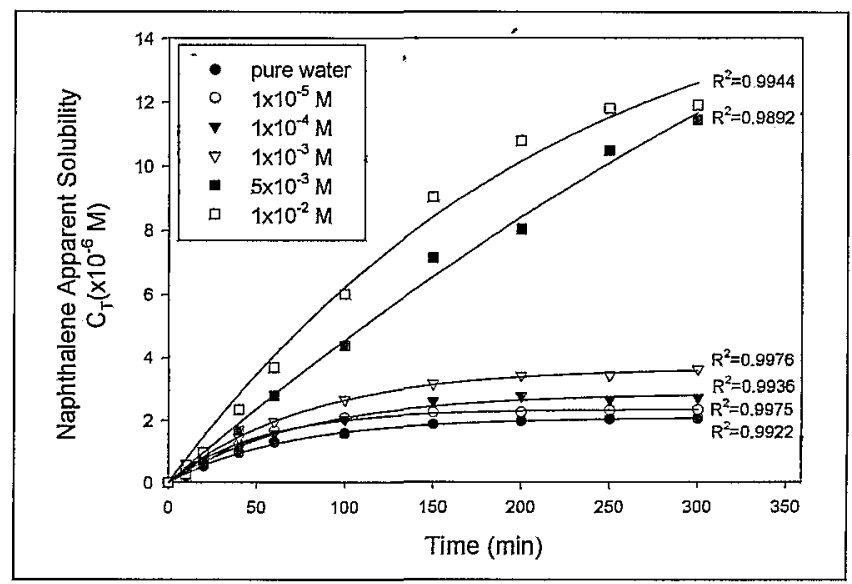

Figure 2. Change of naphthalene apparent solubility with time at different $\mathrm{C}_{10} E_{8}$ concentrations. 


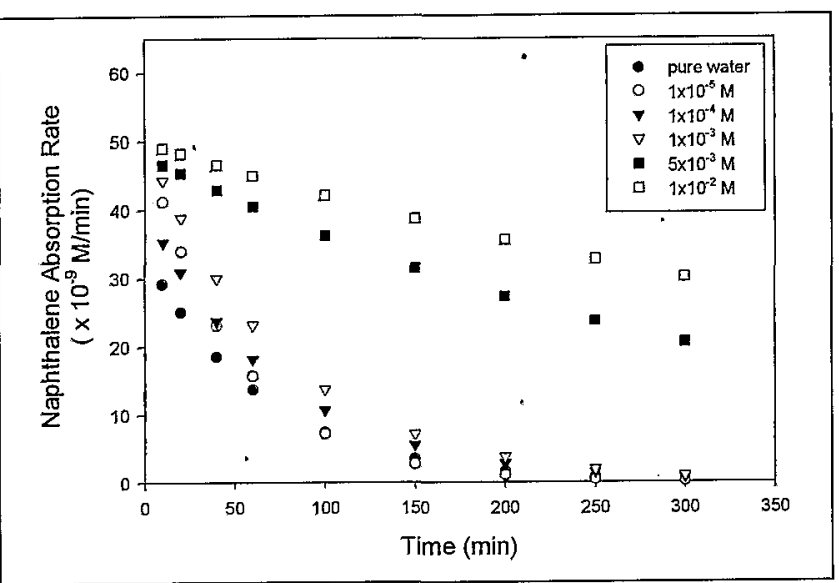

Figure 3. Change of naphthalene absorption rate with time at different $\mathrm{C}_{10} \mathrm{E}_{4}$ concentrations.

slightly with the surfactant concentration. However, the equilibrium apparent solubility or $H^{\prime}$ increased proportionally to the surfactant concentration above the CMC. Apparently, when the surfactant concentration above the CMC is increased, micelle formation also increases and then solubilizes more naphthalene.

Table 2 also indicates that equilibrium naphthalene apparent solubility or $H^{\prime}$ of three polyoxyethylenated nonionic surfactants was significantly greater than anionic SDS surfactant. The CMCs of the three polyoxyethylenated nonionic surfactants ${ }^{32}$ ranged from $7.3 \times 10^{-6}$ to $6.2 \times 10^{-4} \mathrm{M}$, and the $\mathrm{SDS}^{25}$ was $9.2 \times 10^{-3} \mathrm{M}$. The CMC of polyoxyethylenated nonionic surfactants was found to be smaller than anionic SDS surfactant and the formation of nonionic surfactant micelles occurred at a lower surfactant concentration relative to anionic SDS surfactant. Consequently, polyoxyethylenated nonionic surfactants have larger micelle aggregation numbers at surfactant concentrations above the CMC. The more micelles are formed, the more hydrophobic naphthalene molecules are solubilized. Therefore, the solubilization capacity of polyoxyethylenated nonionic surfactants was higher than that of anionic SDS surfactant. However, $\mathrm{C}_{14} \mathrm{E}_{8}$ does not have the highest solubilization ability but has the lowest $\mathrm{CMC}$ value as compared with $\mathrm{C}_{10} \mathrm{E}_{4}$ and $\mathrm{C}_{10} \mathrm{E}_{8}$. These results suggest that there are other important factors that still need to be considered in addition to the CMC value to determine the solubilization capacity of various surfactants for hydrophobic naphthalene.

\section{Effects of Surfactants on Naphthalene Absorption}

The hydrophilic or hydrophobic properties of surfactants were associated with the parameter of HLB. HLB is one of the important characteristics of surfactants and is commonly used as a measure for surfactant hydrophobicity. Surfactant hydrophilicity increases with HLB values. The calculated HLB values shown in Table 1 indicate that the hydrophobicity of surfactants were in the order $\mathrm{C}_{10} \mathrm{E}_{4}>$ $\mathrm{C}_{14} \mathrm{E}_{8}>\mathrm{C}_{10} \mathrm{E}_{8}$. It suggests the ease of attraction of hydrophobic naphthalene in monomers and in micelles caused by the chemical effect "like dissolves like" and was in the order $\mathrm{C}_{10} \mathrm{E}_{4}>\mathrm{C}_{14} \mathrm{E}_{8}>\mathrm{C}_{10} \mathrm{E}_{8}$. As shown in Table 1, HLB values for polyoxyethylenated nonionic surfactants are smaller than 15, which is lower than that of anionic SDS. The HLB value of SDS is $40 .{ }^{33}$ Anionic SDS surfactant has a high percentage of polar head groups and is more soluble in water than are polyoxyethylenated nonionic surfactants. Owing to the hydration effect, SDS has less capability to attract hydrophobic naphthalene than do polyoxyethylenated nonionic surfactants.

Although HLB can be expressed as the hydrophobicity of surfactants, HLB value alone is not a good indicator of surfactant effectiveness for absorbing hydrophobic

Table 2. Equilibrium naphthalene apparent solubility $\left(C_{\mathrm{T}}^{\mathrm{T}}\right)$ and the apparent Henry's Constant $\left(H^{\prime}\right)$ for various surfactant concentrations.

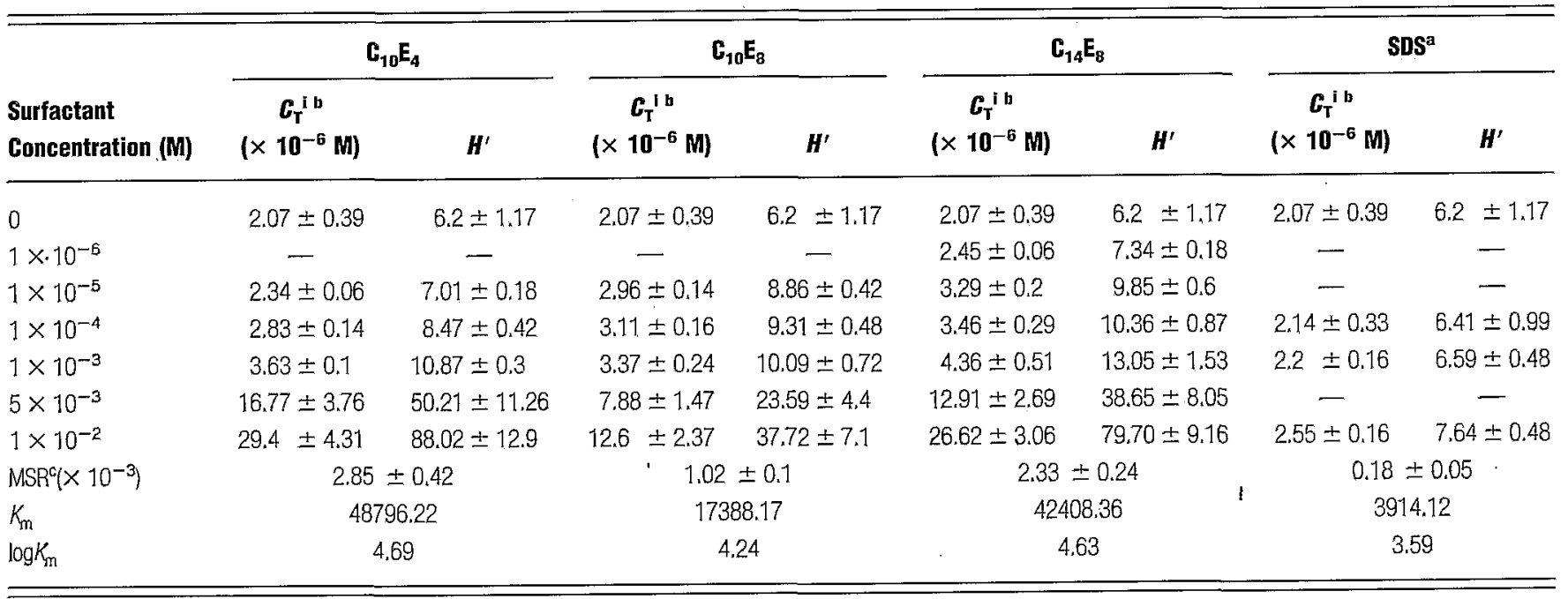

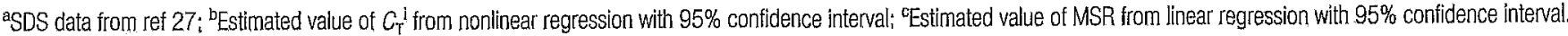


contaminants because the chemical structure of the surfactant is also very important. ${ }^{8} \mathrm{C}_{10} \mathrm{E}_{4}$ solubilized more naphthalene than did the other two nonionic surfactants in this study (Table 2). This is because $\mathrm{C}_{10} \mathrm{E}_{8}$ has four more hydrophilic ethylene oxide (EO) groups when compared with $\mathrm{C}_{10} \mathrm{E}_{4}$ and can solubilize more hydrophobic naphthalene. $C_{10} E_{8}$ and $C_{14} E_{8}$ have an equal number of EO groups; however, $\mathrm{C}_{10} \mathrm{E}_{8}$ with four-less-hydrophobic hydrocarbon chains solubilizes less hydrophobic naphthalene. $\mathrm{C}_{14} \mathrm{E}_{8}$ has a longer hydrophobic hydrocarbon chain and a longer hydrophilic EO group chain length than $\mathrm{C}_{10} \mathrm{E}_{4} \cdot \mathrm{C}_{14} \mathrm{E}_{8}$ not only forms micelles with a stronger inner core force than $\mathrm{C}_{10} \mathrm{E}_{4}$ at surfactant concentrations above the $\mathrm{CMC}$, but also has a greater chemical steric effect and hydration effect. $\mathrm{C}_{10} \mathrm{E}_{4}$ can solubilize more hydrophobic naphthalene than can $\mathrm{C}_{14} \mathrm{E}_{8}$ owing to these three contrasting effects. To conclude, the order of solubilization capacity for naphthalene was $\mathrm{C}_{10} \mathrm{E}_{4}>\mathrm{C}_{14} \mathrm{E}_{8}>$ $\mathrm{C}_{10} \mathrm{E}_{8}$.

\section{Relationship between HLB and MSR or $\boldsymbol{K}_{\mathbf{m}}$}

The MSR that represents the moles of naphthalene absorption per mole of surfactant is determined according to the slope of a straight line above the $\mathrm{CMC}$ in Figure 4. The MSR values were in the order $\mathrm{C}_{10} \mathrm{E}_{4}>\mathrm{C}_{14} \mathrm{E}_{8}>\mathrm{C}_{10} \mathrm{E}_{8}$. This indicated that $\mathrm{C}_{10} \mathrm{E}_{4}$ enhanced naphthalene solubilization the most, $\mathrm{C}_{14} \mathrm{E}_{8}$ was second, and $\mathrm{C}_{10} \mathrm{E}_{8}$ was the least effective. Table 2 also indicates that anionic SDS surfactant has the lowest MSR compared with these three polyoxyethylenated nonionic surfactants. It is obvious that the effect on enhanced naphthalene solubility from adding SDS surfactant was the smallest. Another parameter, $\mathrm{K}_{\mathrm{m}}$, represents the ratio of naphthalene in the micellar phase to the aqueous phase (see Table 2). The order of the $K_{\mathrm{m}}$ values $\left(\mathrm{C}_{10} \mathrm{E}_{4}>\mathrm{C}_{14} \mathrm{E}_{8}>\mathrm{C}_{10} \mathrm{E}_{8}>\mathrm{SDS}\right)$ is consistent with the previous discussion and the order of solubilization capability was $\mathrm{C}_{10} \mathrm{E}_{4}>\mathrm{C}_{14} \mathrm{E}_{8}>\mathrm{C}_{10} \mathrm{E}_{8}>$ SDS. In

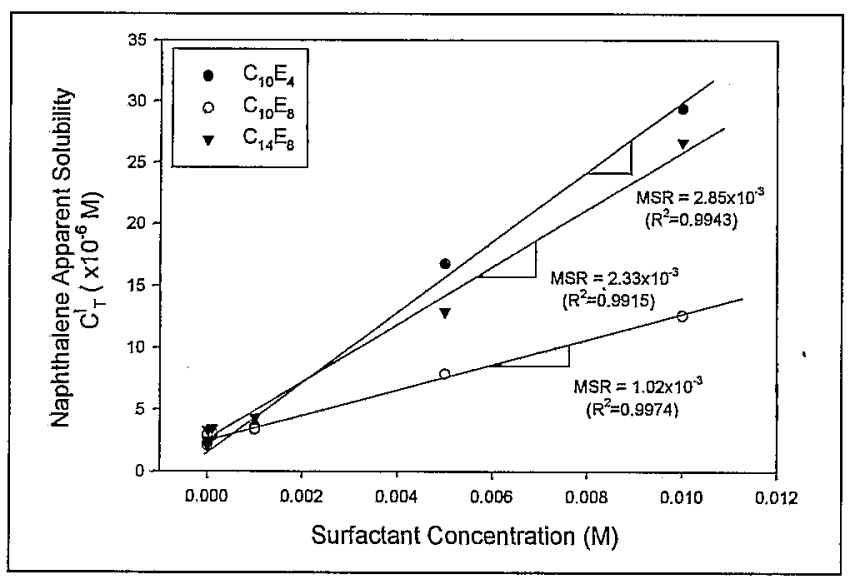

Figure 4. Equilibrium naphthalene apparent solubility at different surfactant concentrations. summary, the extent of naphthalene solubilization can be described by MSR and $K_{\mathrm{m}}$. The previous discussion also indicates that the solubilization effect of micelles is related to the HLB value of the surfactant. Figure 5 shows the relationship between $\mathrm{HLB}, \mathrm{MSR}$, and $K_{\mathrm{m}}$ values. When the HLB values of surfactants increased, logMSR and $\log K_{\mathrm{m}}$ decreased. In comparison with anionic SDS surfac$\operatorname{tant}{ }^{27}$ the three polyoxyethylenated nonionic surfactants have higher MSR and $K_{\mathrm{m}}$ values and lower HLB value. This means that removal efficiency of vapor-phase naphthalene using nonionic surfactants was higher than for SDS. Therefore, HLB values were similar to the parameters of MSR or $K_{\mathrm{m}}$ in representing the solubilization capacity of naphthalene. The HLB value also can be a good indicator for choosing the appropriate surfactant to absorb vaporous-phase naphthalene in this study.

\section{The Lumped Mass Transfer Coefficient}

Figure 6 illustrates the lumped mass transfer coefficients of naphthalene, $k_{\mathrm{L}}{ }^{\prime} a^{\prime}\left(\mathrm{sec}^{-1}\right)$, as a function of surfactant concentration. When surfactant concentrations increased, the $k_{\mathrm{L}}{ }^{\prime} a^{\prime}$ values of naphthalene estimated by nonlinear regression depicted in Figure 2 decreased from $2.53 \times 10^{-4} \mathrm{sec}^{-1}$ to $2.80 \times 10^{-5} \mathrm{sec}^{-1}$. These empirical findings are consistent with earlier findings, $27,35,36$ indicating that $k_{\mathrm{L}}{ }^{\prime} a^{\prime}$ values decrease with the surfactant concentration. In addition, Table 3 and Figure 6 show the viscosities of three nonionic surfactants at various surfactant concentrations. The viscosities of $\mathrm{C}_{10} \mathrm{E}_{4}$ were found to increase with surfactant concentration; however, the viscosities of $\mathrm{C}_{10} \mathrm{E}_{8}$ and $\mathrm{C}_{14} \mathrm{E}_{8}$ did not change at surfactant concentrations below and above the CMC and were the same as pure water (Bonferroni test, $95 \%$ confidence interval). The decrease in $k_{\mathrm{L}}{ }^{\prime} a^{\prime}$ of naphthalene in $\mathrm{C}_{10} \mathrm{E}_{4}$ solution could be because of three reasons. First, the interfacial resistance increases when surfactant monomers aggregate at the gas/liquid interface. The surfactant monolayer prevents naphthalene molecules from entering the solution. Second, the viscosity of the $\mathrm{C}_{10} \mathrm{E}_{4}$ solution increases and then decreases the diffusion rate of the large spherical micelle and small naphthalene molecules. Third, when the surfactant concentration is higher than CMC, micelles contain naphthalene molecules, which then reduce the diffusion rate of the large spherical micelle more than small naphthalene molecules. However, only the first and third reasons for decreasing the $k_{\mathrm{L}}{ }^{\prime} a^{\prime}$ in $\mathrm{C}_{10} \mathrm{E}_{8}$ and $\mathrm{C}_{14} \mathrm{E}_{8}$ solution could be relevant because the viscosities of $\mathrm{C}_{10} \mathrm{E}_{8}$ and $\mathrm{C}_{14} \mathrm{E}_{8}$ did not change with surfactant concentrations.

Experimental findings from this study also indicate that the $k_{\mathrm{L}}{ }^{\prime} a^{\prime}$ in the $\mathrm{C}_{10} \mathrm{E}_{8}$ solution was higher in comparison with $\mathrm{C}_{10} \mathrm{E}_{4}$ and $\mathrm{C}_{14} \mathrm{E}_{8}$ and the $k_{\mathrm{L}}{ }^{\prime} a^{\prime}$ of the $\mathrm{C}_{10} \mathrm{E}_{4}$ and $\mathrm{C}_{14} \mathrm{E}_{8}$ solutions was close. It is possible that naphthalene 


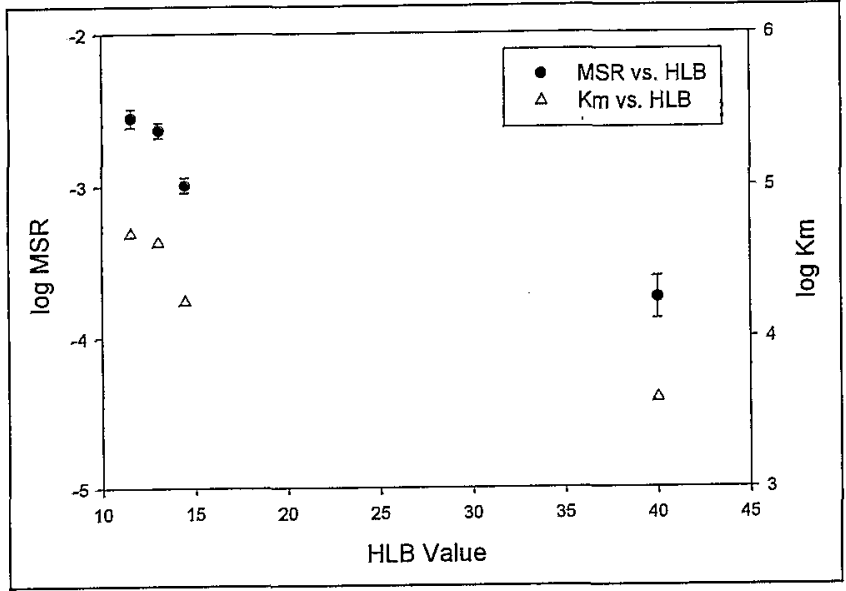

Figure 5. Relationship between $H\left\llcorner B, M S R\right.$, and $K_{m}$ for various surfactants.

in the $\mathrm{C}_{10} \mathrm{E}_{8}$ solution had less resistance because of its lower viscosity compared with the $\mathrm{C}_{10} \mathrm{E}_{4}$ solution. Although there were no viscosity differences between water, $\mathrm{C}_{14} \mathrm{E}_{8}$, and $\mathrm{C}_{10} \mathrm{E}_{8}, \mathrm{C}_{14} \mathrm{E}_{8}$ had a longer hydrocarbon chain length and bigger micelle volume than $\mathrm{C}_{10} \mathrm{E}_{8}$. Therefore, the $k_{\mathrm{L}}{ }^{\prime} a^{\prime}$ in $\mathrm{C}_{10} \mathrm{E}_{8}$ solution was higher than in the $\mathrm{C}_{14} \mathrm{E}_{8}$ solution owing to the greater gas/liquid interface resistance and lower diffusion rate of the large spherical micelle. Similarly, $\mathrm{C}_{10} \mathrm{E}_{4}$ had smaller gas/liquid interface resistance and lower diffusion rate of the large spherical micelle. However, $\mathrm{C}_{10} \mathrm{E}_{4}$ had higher viscosity than $\mathrm{C}_{14} \mathrm{E}_{8}$. The net effect of these factors made the $k_{\mathrm{L}}{ }^{\prime} a^{\prime}$ in $\mathrm{C}_{10} \mathrm{E}_{4}$ and $\mathrm{C}_{14} \mathrm{E}_{8}$ solutions function in a similar way.

Although the lumped mass transfer coefficients decreased with surfactant concentration, the naphthalene absorption rates increased (Figure 6). According to naphthalene absorption kinetics (eq 1), the lumped mass transfer coefficient and naphthalene concentration gradient driving force affect absorption rate. The lumped mass transfer coefficient decreased with the increase of surfactant concentration because of the

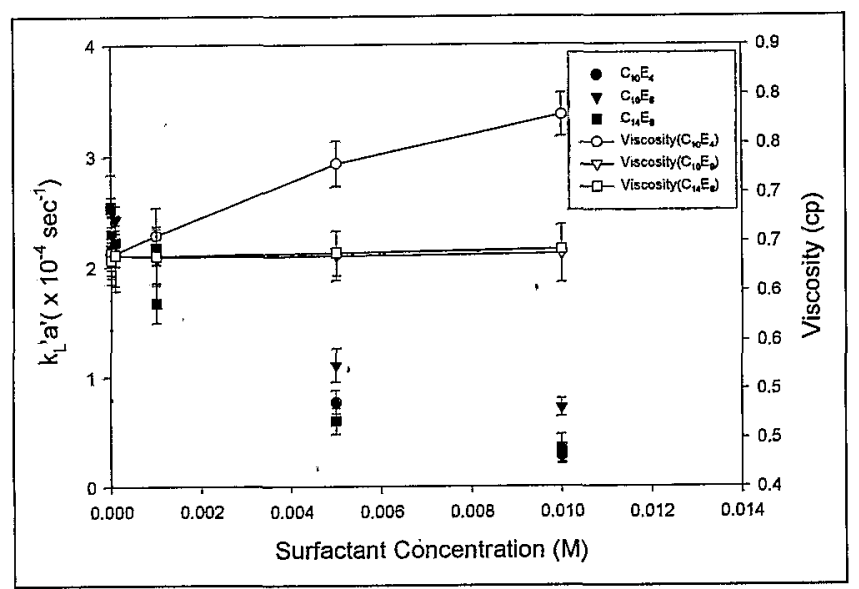

Figure 6. Change of lumped mass transfer coefficients and viscosity at different surfactant concentrations.
Table 3. Viscosity of polyoxyethylenated nonionic surfactants at $50^{\circ} \mathrm{C}$ (Brookfield mode) DV-fll with spindle at $40 \mathrm{rpm}, 95 \%$ confidence interval).

\begin{tabular}{lccc}
\hline \hline \multirow{2}{*}{$\begin{array}{l}\text { Surfactant } \\
\text { Concentration (M) }\end{array}$} & $\mathbf{C}_{\mathbf{1 0}} \mathbf{E}_{\mathbf{4}}$ & $\mathbf{G}_{\mathbf{1 0}} \mathbf{E}_{\mathbf{8}}$ & $\mathbf{C}_{\mathbf{1 4}} \mathbf{E}_{\mathbf{8}}$ \\
\hline & $0.636 \pm 0.019$ & $0.636 \pm 0.019$ & $0.636 \pm 0.019$ \\
0 & - & - & $0.639 \pm 0.017$ \\
$1 \times 10^{-6}$ & $0.637 \pm 0.029$ & $0.636 \pm 0.01$ & $0.632 \pm 0.018$ \\
$1 \times 10^{-5}$ & $0.639 \pm 0.039$ & $0.637 \pm 0.037$ & $0.637 \pm 0.031$ \\
$1 \times 10^{-4}$ & $0.657 \pm 0.029$ & $0.635 \pm 0.026$ & $0.636 \pm 0.03$ \\
$1 \times 10^{-3}$ & $0.73 \pm 0.023$ & $0.636 \pm 0.025$ & $0.639 \pm 0.023$ \\
$5 \times 10^{-3}$ & $0.779 \pm 0.022$ & $0.638 \pm 0.029$ & $0.642 \pm 0.02$ \\
$1 \times 10^{-2}$ & & & \\
\hline \hline
\end{tabular}

formation of micelles, while the equilibrium naphthalene apparent solubility $\left(C^{\mathbf{i}}{ }_{\mathrm{T}}\right)$ increased (as shown in Table 2). The magnitude of the micelle solubilization effect, which increased the naphthalene concentration gradient driving force, was greater than the reduced mass transfer effect, thus causing the total gas absorption rate to increase.

\section{The Enxichment Factor}

The degree of the increase in the solubility of vaporous naphthalene by adding a surfactant can be expressed as the enrichment factor (EF). EF is defined as the ratio of naphthalene moles within surfactant solution to the number of naphthalene moles in pure water. Table 4 presents the EF of naphthalene, which serve as a function of surfactant concentration. At surfactant concentrations lower than the $\mathrm{CMC}$, the $\mathrm{EF}$ values increased slightly. However, the EF values increased dramatically as the surfactant concentration was above the CMC. At a surfactant concentration of $0.01 \mathrm{M}$, which is the highest concentration employed in naphthalene absorption, the $\mathrm{EF}$ value increased to $14.20,6.09$, and 12.86 for $\mathrm{C}_{10} \mathrm{E}_{4}, \mathrm{C}_{10} \mathrm{E}_{8}$, and $\mathrm{C}_{14} \mathrm{E}_{8}$, respectively. Surfactant monomers only have a

Table 4. EF of naphthalene for various surfactant concentrations.

\begin{tabular}{lcccc}
\hline \hline \multirow{2}{*}{$\begin{array}{l}\text { Surfactant } \\
\text { Concentration (M) }\end{array}$} & $\mathbf{C}_{\mathbf{1 0}} \mathbf{E}_{\mathbf{4}}$ & $\mathbf{G}_{\mathbf{1 0}} \mathbf{E}_{\mathbf{8}}$ & $\mathbf{G}_{\mathbf{1 4}} \mathbf{E}_{\mathbf{8}}$ & $\mathbf{S D S}^{\mathbf{a}}$ \\
\hline 0 & 1 & 1 & 1 & 1 \\
$1 \times 10^{-6}$ & - & - & 1.18 & - \\
$1 \times 10^{-5}$ & 1.13 & 1.43 & 1.59 & - \\
$1 \times 10^{-4}$ & 1.37 & 1.5 & 1.67 & 1.03 \\
$1 \times 10^{-3}$ & 1.75 & 1.63 & 2.11 & 1.06 \\
$5 \times 10^{-3}$ & 8.1 & 3.81 & 6.24 & - \\
$1 \times 10^{-2}$ & 14.2 & 6.09 & 12.86 & 1.23 \\
$5 \times 10^{-2}$ & - & - & - & 4.60 \\
$1 \times 10^{-1}$ & - & - & - & 9.05 \\
\hline \hline
\end{tabular}

aSDS data from ref 27. 
limited effect on increasing naphthalene solubility as previously indicated. Surfactants would strongly enhance the naphthalene apparent solubility only at surfactant concentrations higher than the CMC because of the solubilization effect of micelles. The EF values of polyoxyethylenated nonionic surfactants all were greater than anionic SDS at every surfactant concentration. This is because these polyoxyethylenated nonionic surfactants havemore hydrophobicity with lower HLB and CMC than anionic SDS. Therefore, the nonionic surfactant monomers at surfactant concentrations below the CMC or forming micelles at above the CMC can solubilize more naphthalene than SDS.

Table 4 indicates that the nonionic surfactant solution at $1 \times 10^{-5} \mathrm{M}$ has the same ability as anionic SDS surfactant solution near the $\mathrm{CMC}$ at $1 \times 10^{-2} \mathrm{M}$ and can enhance naphthalene solubility 1.23 times more than pure water. If the degree of naphthalene enhancement is acceptable, the nonionic surfactants will be more economical for this absorption system, because anionic SDS surfactants are 3 orders more expensive than polyoxyethylenated nonionic surfactants. Similarly, the nonionic surfactant solution at $1 \times 10^{-2} \mathrm{M}$ has the same ability as anionic SDS surfactant solution at $1 \times 10^{-1} \mathrm{M}$ to increase the level of naphthalene solubility to 9.05 times the solubility from pure water. The cost of purchasing anionic SDS surfactants was higher than that of nonionic surfactants by 1 order of magnitude. Because all polyoxyethylenated nonionic surfactants and anionic SDS surfactants are nontoxic and biodegradable, cost analysis would be an important factor in determining the optimal surfactant for absorption of naphthalene. In summary, greater absorption removal efficiency with naphthalene was achieved by adding polyoxyethylenated nonionic surfactants rather than anionic SDS surfactants in water at the same surfactant concentration.

\section{CONCLUSIONS}

The effect of adding polyoxyethylenated nonionic surfactants on the solubility of vaporous naphthalene in water was examined in this study. Naphthalene's apparent solubility or absorption rate at surfactant concentrations lower than the CMC was about the same as with pure water; however, it increased dramatically with surfactant concentrations above the CMC. It is evident that adding polyoxyethylenated nonionic surfactants significantly increases the absorption efficiency of the HOC, naphthalene. The role of monomers and micelles of polyoxyethylenated nonionic surfactants in enhancing the solubility of naphthalene was similar to and even better than the monomers and micelles of anionic SDS surfactant. They can solubilize more naphthalene at surfactant concentrations both below and above the CMC. This research may provide a useful reference for researchers and managers attempting to develop control technology for vaporous naphthalene by spray or packed tower.

\section{ACKNOWLEDGMENTS}

The authors thank the National Science Council of the Republic of China for financially supporting this research under grant No. NSC 89-2211-E-002-097.

\section{REFERENCES}

I. Wey, M.Y.; Ou, W.Y,; Liu, Z.S.; Tseng, H.H.; Yang, W.Y.; Chiang, B.C. Pollutants in Incineration Flue Gas; J. Hazard. Mater. 2001, B82, 247 262.

2. Li, C.T; Lee, W.J.; Mi, H.H.; Su, C.C. PAH Emission from the Incineration of Waste Oily Sludge and PE Plastic Mixtures; Sci. Total Environ. 1995, 170, 171-183.

3. Wey, M.Y.; Yu, L.J.; Jou, S.I.; Chiang, B.C.; Wei, M.C. Adsorption of Carbon and Zeolite of Pollutants from Flue Gas during Incineration; J. Environ. Eng. 1999, 125 (10), 925-932.

4. Chiang, B.C.; Wey, M.Y.; Yang, W.Y. Control of Incinerator Organics by Fluidized Bed Activated Carbon Adsorber; J. Environ. Eng. 2000, 126 (11), 985-992.

5. Mastral, A.M.; Gracía, T,; Callén, M.S; Navarro, M.V.; Galbán, J. Removal of Naphthalene, Phenanthrene, and Pyrene by Sorbents from Hot Gas; Environ. Sci. Technol. 2001, 35 (11), 2395-2400.

6. Mulligan, C.N.; Yong, R.N.; Gibbs, B.F. Remediation Technologies for Metal-Contaminated Soils and Groundwater: An Evaluation; Eng. Geol. 2001, 60 (1-4), 193-207.

7. Mulligan, C.N.; Yong, R.N.; Gibbs, B.F. Surfactant-Enhanced Remediation of Contaminated Soil: A Review; Eng. Geol. 2001, 60 (1-4), 371380 .

8. Lee, D.H.; Cody, R.D.; Hoyle, B.L. Laboratory Evaluation Remediation of the Use of Surfactants for Ground Water Remediation and the Potential for Recycling Them; Ground Wat. Monitor. Rem. 2001, 21 (1), 49-57.

9. Deshpande, S.; Shiau, B.J.; Wade, D.; Sabatini, D.A.; Harwell, J.H. Surfactant Selection for Enhancing Ex Situ Soil Washing; Water Res. 1999, 33 (2), 351-360.

10. Kanga, S.A.; Bonner, J.S.; Page, C.A.; Mills, M.A.; Autenrieth, R.L. Solubilization of Naphthalene and Methyl-Substituted Naphthalenes from Crude Oil Using Biosurfactants; Environ. Sci. Technol. 1997, 31, 556-561.

11. Rosen, M.J. Surfactants and Interfacial Phenomena; Wiley \& Sons: New York, 1989.

12. Edwards, D.A.; Liu, Z.; Luthy, R.G. Interactions between Nonionic Surfactant Monomers, Hydrophobic Organic Compounds and Soil; Water Sci. Technol. 1992, 26 (1-2), 147-158.

13. Edwards, D.A.; Luthy, R.G.; Liu, Z. Solubilization of Polycyclic Aromatic Hydrocarbons in Micellar Nonionic Surfactant Solutions; Environ. Sci. Technol. 1991, 25 (1), 127-133.

14. Liu, Z.; Laha, S.; Luthy, R.G. Surfactant Solubilization of Polycyclic Aromatic Hydrocarbon Compounds in Soil-Water Suspensions; Water Sci. Technol, 1991, 23, 475-485.

15. Yeom, I.T.; Ghosh, M.M.; Cox, C.D; Robinson, K.G. Micellar Solubilization of Polynuclear Aromatic Hydrocarbons in Coal Tar-Contaminated Soils; Environ. Sci. Technol. 1995, 29 (12), 3015-3021.

16. Paterson, I.F.; Chowdhry, B.Z.; Leharne, S.A. Polycyclic Aromatic Hy drocarbon Extraction from a Coal Tar-Contaminated Soil Using Aqueous Solutions of Nonionic Surfactants; Chemosphere 1999, 38 (13), 3095-3107.

17. Guha, S.; Jaffé, P.R.; Peters, C.A. Solubilization of PAH Mixtures by a Nonionic Surfactant; Environ. Sci. Technol. 1998, 32 (7), 930-935.

18. King, A.D., Jr. Solubilization of Gases; In Solubilization in Surfactant Aggregates; Christian, S.D., Scamehorn, J.F., Eds.; Surfactant Science Series 55; Dekker: New York, 1995; pp 35-58.

19. King, A.D., Jr. Solubilization of Gases by Poly(ethylene oxide)Poly(propylene oxide) Triblock Copolymers; I. Colloid Interface Sci. 2001, 244 (1), 123-127.

20. Radwan, N.; King, A.D., Jr. Solubilization of Gases by Polyethoxylated Octyl Phenols; J. Colloid Interface Sci. 1997, 194, 120-126.

21. An, Y.J.; Carraway, E.R.; Schlautman, M.A. Solubilization of Polycyclic Aromatic Hydrocarbons by Perfluorinated Surfactant Micelles; Water Res. $2002,36(1), 300-308$.

22. Lo, J.H.A.; Lee, W.M.G. Effect of Surfactant Film on Solubility of Hydrophobic Organic Compounds in Fog Droplets; Chemosphere 1996, 33 (7), 1391-1408. 
23. Hai, M.; Han, B.; Yang, G.; Yan, H.; Han, Q. Effect of $\mathrm{NaCl}, \mathrm{NaOH}$, and Poly(ethylene oxide) on Methane Solubilization in Sodium Dodecyl Sufate Solutions; Langmuir 1999, 15 (5), 1640-1643.

24. Steinberg, S.M.; Swallow, C.E.; Ma, W.K. Vapor Phase Sorption of Benzene by Cationic Surfactant Modified Soil; Chemosphere 1999, 38 (9), 2143-2152.

25. Huang, HL. Lee, W.M.G. Simultaneous Absorption of Vapor Phase Polycyclic Aromatic Hydrocarbon and Carbon Dioxide in an Anionic Surfactant Solutions; J. Environ. Sci. Health, A 2001, 36 (7), 1187-1204.

26. Huang, H.L.; Lee, W.M.G. Enhanced Naphthalene Solubility in the Presence of Sodium Dodecyl Sulfate: Effect of Critical Micelle Concentration; Chemosphere 2001, 44 (5), 963-972.

27. Huang, H.L- Lee, W.M.G. Simultaneous Removal of Naphthalene and Sulfur Dioxide Using Surfactant; J. Environ. Eng. 2002, 128 (1), 60-67.

28. Valsaraj, K.T.; Thibodeaux, L.J. Relationships between Micelle-Water and Octanol-Water Partition Constants for Hydrophobic Organics of Environmental Interest; Water Res. 1989, 23 (2), 182-198.

29. Locating and Estimating Air Emissions from Sources of Polycyclic Organic Matter (POM); EPA-450/4-84-007p; U.S. Environmental Protection Agency: Research Triangle Park, NC, 1987.

30. Arthur, C.L.; Potter, D.W.; Buchholz, K.D.; Motlagh, S.; Pawliszyn, J. Solid-Phase Microextraction for the Direct Analysis of Water: Theory and Practice; Separ. Sci. 1992, 10 (9), 656-661.

31. Lee, S.J.; Chang, C.Y.; Chiu, C.Y.; Huang, W.H.; Shih, S.M. Simple Approximate Solutions of Internal Circulation Periods of Liquid in Falling Droplets; $J$. Chin. Inst. Chem. Eng. 1998, 29 (6), 421-426.

32. Chen, L.J.; Lin, S.Y.; Huang, C.C.; Chen, E.M. Temperature Dependence of Critical Micelle Concentration of Polyoxyethylenated NonIonic Surfactants; Colloids Surf. A 1998, 135, 175-181.

33. Jafvert, C.T.; Van Hoof, P.L.; Heath, J.K. Solubilization of Non-Polar Compounds by Non-Ionic Surfactant Micelles; Water. Res. 1994, 28 (5), 1009-1017.
34. Kile, D.E.; Chiou, C.T. Water Solubility Enhancements of DDT and Trichlorobenzene by Some Surfactants below and above the Critical Micelle Concentration; Environ. Sci. Technol. 1989, 23 (7), 832-838.

35. Grimberg, S.J.; Nagel, J.; Aitken, M.D. Kinetics of Phenanthrene Dissolution into Water in the Presence of Nonionic Surfactants; Environ. Sci. Tecinol. 1995, 29 (6), 1480-1487.

36. Mulder, H.; Breure, A.M.; Van Andel, J.G.; Grotenhuis, J.T.C.; Rulkens, W.H. Influence of Hydrodynamic Conditions on Naphthalene Dissolution and Subsequent Biodegradation; Biotechnol. Bioeng. 1998, 57 (2), $145-154$.

\section{About the Authors}

Hsiao-Lin Huang received his Ph.D. from the Graduate Institute of Environmental Engineering at National Taiwan University in 2001. He is now performing alternative military service with the Taiwanese Environmental Protection Administration. Whei-May Grace Lee is a professor in the Graduate Institute of Environmental Engineering at National Taiwan University. She received her Ph.D. in environmental engineering from Purdue University in 1985. Address correspondence to: Whei-May Grace Lee; fax: 886-223633249; e-mail: gracelee@ccms.ntu.edu.tw. 


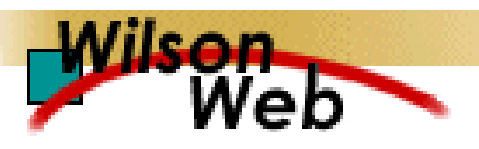

\section{COPYRIGHT INFORMATION}

TITLE: Removal of Vaporous Naphthalene Using Polyoxyethylenated Nonionic Surfactants

SOURCE: J Air Waste Manage Assoc (1995) 53 no8 Ag 2003

WN: 0321305991008

The magazine publisher is the copyright holder of this article and it is reproduced with permission. Further reproduction of this article in violation of the copyright is prohibited. To contact the publisher: http://www.awma.org/

Copyright 1982-2003 The H.W. Wilson Company. All rights reserved. 